\title{
Social Media Influencers and Purchase Intention amongst Social Media Users in developing African economy
}

\author{
Ebuka Christian Ezenwafor ${ }^{*} \oplus$, Chigbata Moses Olise $^{2} \odot$, Promise Ikechukwu Ebizie ${ }^{2} \odot$
}

Western Illinois University Macomb, Illinois, USA

2 Marketing Department, Nnamdi Azikiwe University, Nigeria

* Corresponding Author (ezenwafor@wiu.edu)

Received: 11 May, 2021

Revised: 25 August, 2021

Accepted: 10 November, 2021

Published: 25 December, 2021

How to cite this paper:

Ezenwafor, E.C., Olise, C.M. \& Ebizie, P. I. (2021). Social media influencer and purchase intention amongst social media users in developing African economy. Quest Journal of Management and Social Sciences, 3(2), pp. 217-228.
Copyright (C) 2021 by authors and Quest Journal of Management and Social Sciences.

This work is licensed under a Creative Commons Attribution-Non Commercial-No Derivatives 4.0 International License.

https://creativecommons.org/ licenses/by-nc-nd/4.0/

\section{Abstract}

Background: Internet disruption has unprecedentedly made social media a global village and global digital market where business and customers interacts boundlessly. People's interaction has far gone beyond boundary and businesses are seeing and harnessing these opportunities.

Objective: This study investigated the effect of social media influencers on purchase intention among social media users.

Method: The population of this study consist of active social media users in Anambra state. Sample size of 220 was arrived at using convenience sampling for infinite population. Reliability and validity test were done through construct Reliability and Discriminant validity respectively through smart- pls. Data was computed with SPSS version 24 and analysed with SEM via Smart-Pls.

Result: The finding of this investigation showed that trustworthiness, attractiveness and influencer product match up has positive and significant effect on purchase intention respectively.

Conclusion: More so, expertise does not influence purchase intentions. Finally, if there is need social media influencer, organizations should painstakingly seek influencers with high trust level among audience, highly attractive and it's congruity with the intended promoted product.

Paper Types: Research Paper

Key Words: Social Media Influencers; Purchase Intentions; Social Media Users; Source Attractiveness, Source Trustworthiness; Product-Influencer Matchup; Influencer Expertise.

JEL Classification: D91 


\section{Introduction}

The extensive proliferation of technology evidently noticed in almost all the industry has inadvertently altered many business operations, and its interaction with customers and anticipated customers. Organization traditionally operates in a volatile business environment with avid struggle to survive. This struggle has led to changes in their strategies and basic mode of operation. In a bit to adapt to steady shift in customers behaviour, organizations have joined the race to interact with customers over the social media. Contextually, these changes pertain to interaction and advertisement strategies employed by organization to get to the customers who supposedly make online transactions (Peetz, 2012).

Ordinally, organizations use traditionally form of advertisement to interact with the target audience to ensure purchase, as expected, this form has been effective to its own capacity (Xinjean and Hwa, 2019). The cost incur with this form of advertisement is commensurate with the proposed return of investment, making it a manageable form of communication. However, some factors limited the outright success of traditional advertisement. Firstly, time constraint: most of the proposed advertisements are aired at a given time of the day or night hence, limits the number of persons that views the advertisement. Secondly, lack of interaction: unarguably, these advertisements are aimed at telling the audience about the products, it is naturally one sided thus, the customers are limited to just listener of the advertisement. Finally, technical factor amongst host of others limits the total success of traditional forms of advertisement (Ashe-edmunds, 2017).

Over the years, social media has witnessed an increased inflow of users hence, has over 113milion users in 2019 juxtaposed to 92.3 million users in the previous year (Clement, 2019). The incipient of technology and sally growth of social media launched a new phase of interacting with audience through the use of social media influencers. Social media influencers are digital opinion leader with large audience base, who use social media channels to share post with their followers about information, products and experiences they have had with different organizations (Freberg et al., 2010). When compared with other form of celebrity endorsement, Social media influencer is regarded as the helm of affair because of its amiable and steady rapport with the audience (Kumar, 2011). Echoing this popular believe, social media influencer as a brand endorser has grown more sought-after especially amongst new and online business (Xinjean et al., 2019). Furthermore, plethora social media users gave room for social media influencer to flourish. The influencer gives audience the impression that such product is of reliable quality and it is of acceptable quality (Lim et al., 2017). These assumptions presumably motivate the audience to try the product.

Plethora of research has been carried out to investigate the effect of social media influencers on purchase intention in a global facet. Extant investigations on social media influencer focused on theoretical underpinning which discussed various theories of social media influencer (More \& Lingman, 2019; Ge \& Gretzel, 2018; zhao et al., 2018) and conceptual framework which focused on conceptualization of various dimensions of social media influencers (Ferberg et al., 2010; Hearn \& Schoenhoff, 2016; Pang et al., 2016). To the best of our knowledge, empirical investigation on social media influencer and purchase intention is sparse and lacking in a typical sub-Saharan Africa which has a sally promising growth in social media usage. To address this identified literary gap, this study aim to investigate the effect of social media influencer on purchase intentions among social media users in typical growing African state.

The remaining section of the paper is divided into literature review which explains the concepts and what is already known while evaluating the existing knowledge and the direction of this study. Following that is hypotheses development which take covers debate on the dimension. It looks into various angle at which researcher have studied the concepts. Furthermore, research methodology covers the method of collecting data and how best to analyse it while analysis covers the analysis of the work. Finally, interpretation and conclusion looks at the finding, relevance of the study and managerial implication of the study. 


\section{Review of Literature}

\section{Social Media Influencer}

To effectively communicate the existence of product, organizations have to device means to inform audience about the product to ensure the objective of such organization is achieved. The objective of organization is to get produced goods down to customers. This assertion led to organizations trying various means to get product to consumer. Amongst all employable strategies is use of advertisement which has proven its effectiveness in communicating with targeted audience (Morwitz, 2012).

Evidently, advertisement has performed fundamental purpose of communicating the existence, function and anticipated need of the product to audience. Advertising at this time has employed different form of communicating to the consumer (media, bill board, celebrity endorsement and most trendy social media influencer) and has achieved varying level of success. Evolution dynamicity and volatility of marketing environment has reduced efficacy of some form of advertisement hence, making social media marketing, digital marketing, etc more useful. With the increasing customer involvement in social media activities, either for fun, leisure or business motive; cyber-space is now a place where customers can actively engage themselves at various levels. This gave room for proliferation of social media influencers (Weilki, 2020).

Basically, social media influencer is a subset of celebrity endorsement which is a subset of advertisement. According to Satria et al. (2019), social media influencers are identify as internet celebrity due to the fact that they are active users of social media with high level of social media presence and has ability to influence people. Juxtaposed with celebrity endorsement, social media influencers have more clout and influencing ability because over time, they have gained credibility with the customer since the relationship is based on interaction (Satria et al., 2019). Due to interactive nature of social media influencer, messages disseminated by SMI are often seen as more reliable and compelling to customer and has been substantiated by plethora of followers (Talaverina, 2015 as cited by Xinjean et al., 2017). Studies have shown that customers have shifted credence of disseminated information from traditional media (newspapers, television and bill board) to internet especially social media (Johnson \& Kaye, 2004).

\section{Customer Purchase Intention}

Customer purchase intention is one of the most studied concepts of marketing because of its relation to buying behaviour (Morwitz, 2012). Purchase decision refers to a future behaviour of a consumer to possible purchase a particular item when the need arises in the future (Schiffman \& Kanuk, 2000). This concept is use by experts to predict possible sale of a product (Morwitz, 2012). More so, purchase intention is defined as the tendency of a customer to buy the same product based on previous experience. Additionally, it could be that need that propels a consumer towards making a particular purchase (Bhasin, 2018). This aforementioned definition led to the assertion, purchase intention is an embodiment of needs that drive the action to make a particular purchase. More so, purchase intention is laid by need of such product (Bhasin, 2018). Purchase intentions are dynamic hence, varies at any point in time. Many factors affect consumer purchase intention varying from psychological (internal) to physical (external) attributes (Morwitz, 2012). This variation gives room for every organization to actively ensure that its product appeals to consumers and of choice whenever a consumer wants to make a purchase.

\section{Theoretical Framework}

This study is anchored on theory of source credibility as propounded by Ohinian(1991) termed Ohinian model of source credibility. Generally, source credibility relates to pattern of communication between sender and audience. In a typical marketing/ business environment, it is the process of communicating 
with targeted segment (Corina, 2010). Source credibility model is an amalgam of two different models; source credibility and source attraction model (Fred, 2015). More so, the model is one of the highly validated models of business communication between the communicator and audience. In a practical sense of it, for a message to be totally accepted and regarded, there should be some degree of truth, attraction, expertise and match-up expected from the communicator. According to Belch and Belch (2004), source credibility is the extent to which receiver sees the source as to have essential knowledge, skill, experience and trust. Having been merged together, this model unanimously agreed that source credibility has three major dimensions which are; attractiveness, trustworthiness and expertise. In a bid to have a broader view of this model, product match-up is added to have a deeper understand and broader facet of the effect of social media influencer on social media users intention. Figure 1 is the propose model for this study.

\section{Hypotheses Development}

\section{Source Attractiveness and Purchase Intention}

Source attractiveness can be defined as physical attraction of social media influencer (Lim et al., 2017). The physical attractiveness of a social media influencer can be depicted from post and pictures regularly uploaded to social media platform. This is the point of engagement between the social media influencer and targeted audience. Social media influencer with amazing appearance has more tendencies to attract audience attention (Lim et al., 2017). Evidently, source attractiveness is not limited to the influencer's appearance (Shimp, 2004; Langmeyer \& Shank, 1994). The uniqueness, content and currency of such influencer could do more than just bodily appearance. Source attractiveness is further divided into similarity, familiarity, likeability, physical beauty, sexiness and elegance (Peetz, 2012). Plethora existent studies (Liu, Huang, \& Minghua, 2007; Lim et al., 2017 \& Rahayu, \& Arifin, 2020) have established the effect of source attractiveness in influencing purchase intention and behaviour of customer with high congruence in outcome and as well beefs up the existing literatures on source attractiveness. Their findings are quite acceptable in their respective limited scopes as it was conducted in Europe and America. However, to get a clearer picture in a typical sub-Saharan African country, we hypothesize:

H1: There is a positive relationship between source attractiveness and purchase intention.

\section{Source Trustworthiness and Purchase Intention}

Trustworthiness has been a germane principal of even the traditional form of business. For any business to perform successful, and satisfactorily deal with its customer, trust amongst other underpinning factor is highly necessary. According to Erdogan et al. (2001) as cited by Onu et al. (2019), source trustworthiness refers to the unbiased, uprightness and acceptability of an influencer. Customers generally believe that social media influencers are credible source of disseminating information and as such, any passed information is as genuine as the source. In essence, a trusted influencer is more likely to convince the audience to absorb transmitted information (Ferberg et al, 2010). Drawing down to social media influencer, they are generically seen as blogger who transmits unfiltered information for audience consumption (Shimp, 2004). Trustworthiness encompasses influencer uprightness, sincerity and acceptability of such influencer by the proposed audience (Onu et al., 2019). In the words of Shimp (2003), source trustworthiness is the tendency of the source to be believed and trust by audience which can influence their intention as when expected. When a source is reasonably trusted by audience, the behaviour of such audience aligns with that of the influencer. Such audience has a tendency of having similar stake with the influencer on similar cases. Social media influencers' mode of operation enable influencers create and maintain digital mutual or some degree of relationship with his followers. This relationship goes a long way in flourishing trust between the influencer and followers. 
Organizations have previously employed methods of communicating (radio advertising, bill board, television etc.) with the audience which has emanated to various degree of success. Conversely, the level of trust given to the influencer by followers has shown an unprecedented full blown impact on customer's behaviour and intentions in various business sectors (Onu et al, 2019).

$\mathrm{H} 2$ : There is a positive relationship between source trustworthiness and purchase intention.

\section{Influencer Expertise and Purchase Intention}

Expectedly, am influencer is meant to be an expert in whatever form of influencing engaged in. According to Erdogan et al (1999), celebrity expertise is defined as the extent to which an influencer is seen as a source of valid assertion or authority. Expertise has been captured in former research as authoritativeness, qualification and competence of the influencer in delivering information (Ohanian, 1992). More so, expertise euphemistically means not what the influencer is really is but how the audiences see the person. To better buttress the point, an expert is relative from customers view point, what customer sees the influencer as. Influencer can be seen as an expert or just unprofessional person trying to influence customer decision. It is highly important that the customers perceives the influencer as an expert because the level of expertise perceive by the audience influences the customer intention (Ohinian, 1990). Influencers are more perceived as expert if they endorse product or service that pertain to the area that they highly informed in, work area or area of interest (Biswas, Biswas \& Das, 2006). Studies conducted by (Pham \& Nguyen, 2015; Ha \& Lam, 2017) affirmed that celebrity expertise has a significant effect on consumer purchase intentions. Concurringly, Ohanian (1991) posited that in some high expense purchase intention, consumer seeks professional opinion to relatively weigh the option for a better purchase. However, to make a better stance in this situation, we hypothesize H3: source expertise has a significant effect on purchase intention.

\section{Product- influencer Matchup and Purchase intention}

Influencers are always in to influence and change customer purchase intention. Operationally, they exist to inform customers and audience on what best to purchase at any point in time. Plainly, product in this context can be goods, services, organisation and event. Acknowledgement of varying form of products warrant need for different approaches in communicating to audience. Furthermore, influencers are not normally generic thus, they influence differently with different product. More so, the effectiveness of influencer differs among various application and products Ohinian, (1991).

\section{Figure 1. Proposed research schema}

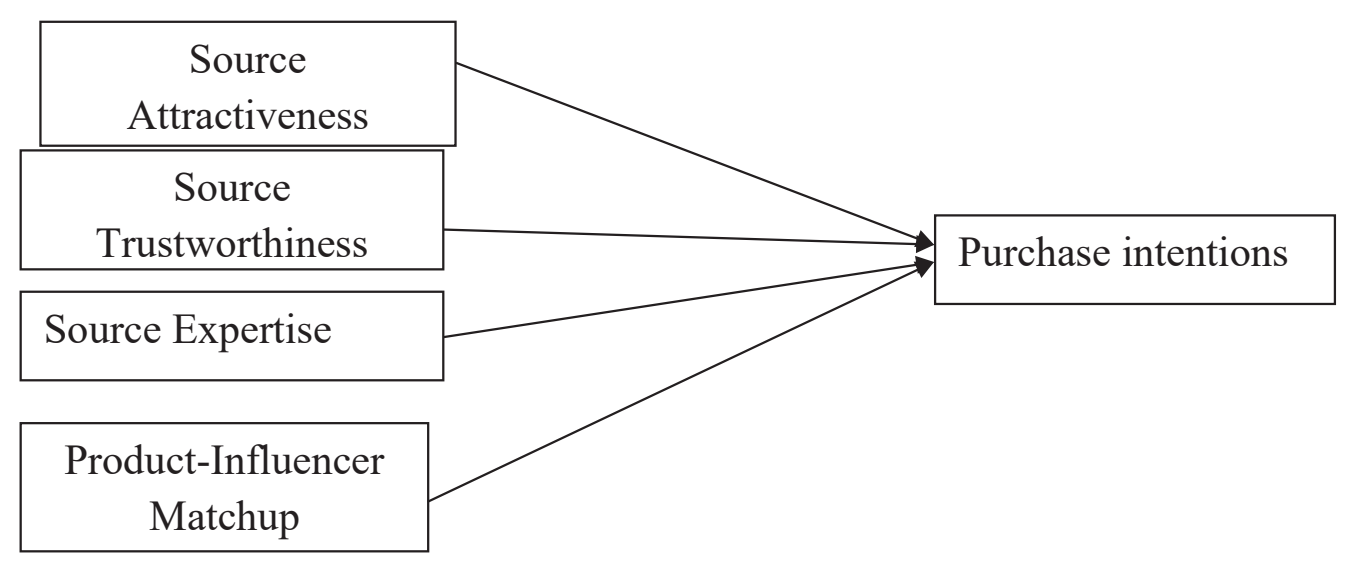

Source: Researchers conceptualization. 
To effectively influence consumer purchase intention, there is a need to appropriately identify influencer that best fit a particular product. This assertion gives root to product-influencer match up. Kamins (1990) believes that endorse are more effective when there is a fit between the endorser and endorsed product. Nam \& Dan (2018) asserted the importance of influencer product congruity in dealing with customer, as it affects customer trust towards the credence of the influencer hence, has a positive effect on purchase intention. Shimp (2008) posits that a matchup between the influencer and the brand is the most germane element in influencing customer purchase intention. . However, to verify this claim, we hypothesize

H4: product-influencer matchup has a significant effect on purchase intention.

\section{Research Methods}

\section{Materials and Methodology}

The population of this study includes active social media users in anambra state. Sample includes selected users of social media which was selected by using convenience sampling which arrived at 220 possible respondents. Data was collected through the administration of questionnaire to 220 respondents who are active users of social media channels in Anambra state, southeast Nigeria while 216 was filled correctly and returned. The inclusion of social media users is to ensure adequacy of anticipated responses.

\section{Measurement}

The questionnaire consist of a 5-point likert-scale from strongly disagree ' 1 ' to strongly agree '5'. Questionnaires were distributed through various social media platform to enable it have verse respondent participation. Quota sampling was employed due to its near probability characteristic. The question items generated for this study consist of 4 social media constructs and 1 purchase intention construct. The social media influencer dimension where extracted from the work of Ohanian (1990) and Ha et al (2017), while question set of purchase intention was culled from Ha et al (2017). 4 items were generated for all the constructs covered in this study. The hypotheses were tested using structural equation modelling via smart-pls. Instrument was validated via discriminant analysis while construct validity was employed to test for reliability.

\section{Data Analysis and Results}

\section{Descriptive Analysis}

Table 1: Demographic characteristic of the respondent

\begin{tabular}{lccc}
\hline \multicolumn{1}{c}{ Characteristics } & Category & Frequency & Percentage \\
\hline Gender & Male & 102 & $42.1 \%$ \\
& Female & 114 & $52.8 \%$ \\
Age & & & \\
& $18-25$ & 17 & $7.9 \%$ \\
& $26-30$ & 122 & $56.5 \%$ \\
Marital status & $31-45$ & 77 & $35.6 \%$ \\
& Single & 143 & $66.2 \%$ \\
& Married & 48 & $22.2 \%$ \\
& Divorced & 18 & $8.3 \%$ \\
& Widow & 7 & $3.2 \%$ \\
\hline \hline https://doi.org/10.3126/qjmss.v3i1.41571 & & & QJMSS (2021)
\end{tabular}




\begin{tabular}{lccc}
\hline \multicolumn{1}{c}{ Characteristics } & Category & Frequency & Percentage \\
\hline Education Qualification & Ssce & 42 & $19.4 \%$ \\
& Hnd/bsc & 162 & $75.0 \%$ \\
& Post-graduate & 12 & $5.6 \%$ \\
Actively using social media & Yes & 152 & $70.4 \%$ \\
& No & 6 & $2.8 \%$ \\
& Sometimes & 36 & $16.7 \%$ \\
which channel do you use most & & & \\
& Facebook & 72 & $33.3 \%$ \\
& Whatsapp & 72 & $33.3 \%$ \\
& Instagram & 30 & $13.9 \%$ \\
& Twitter & 24 & $11.1 \%$ \\
& Others & 18 & $8.3 \%$ \\
\hline
\end{tabular}

From table 1, it was found that 94 persons are male while 114 are female. From age, 18-25 are 17, 26-30 are 122 and 31- 45 are 77 respondent 9respectively. This study is mostly made up of single respondent representing 143 married are 48 while divorced the smallest with 18. Educationally, Hnd/ Bsc took the lead with 162 followed by Ssce 42 and postgraduate occupying 12. From most used social media channel, Facebook and Whatsapp have equal number of respondent 72 and 72 respectively, followed by Instagram with 30, twitter with 24 and finally others scored 18 .

\section{Figure 2: output measurement model via Pls-SEM}

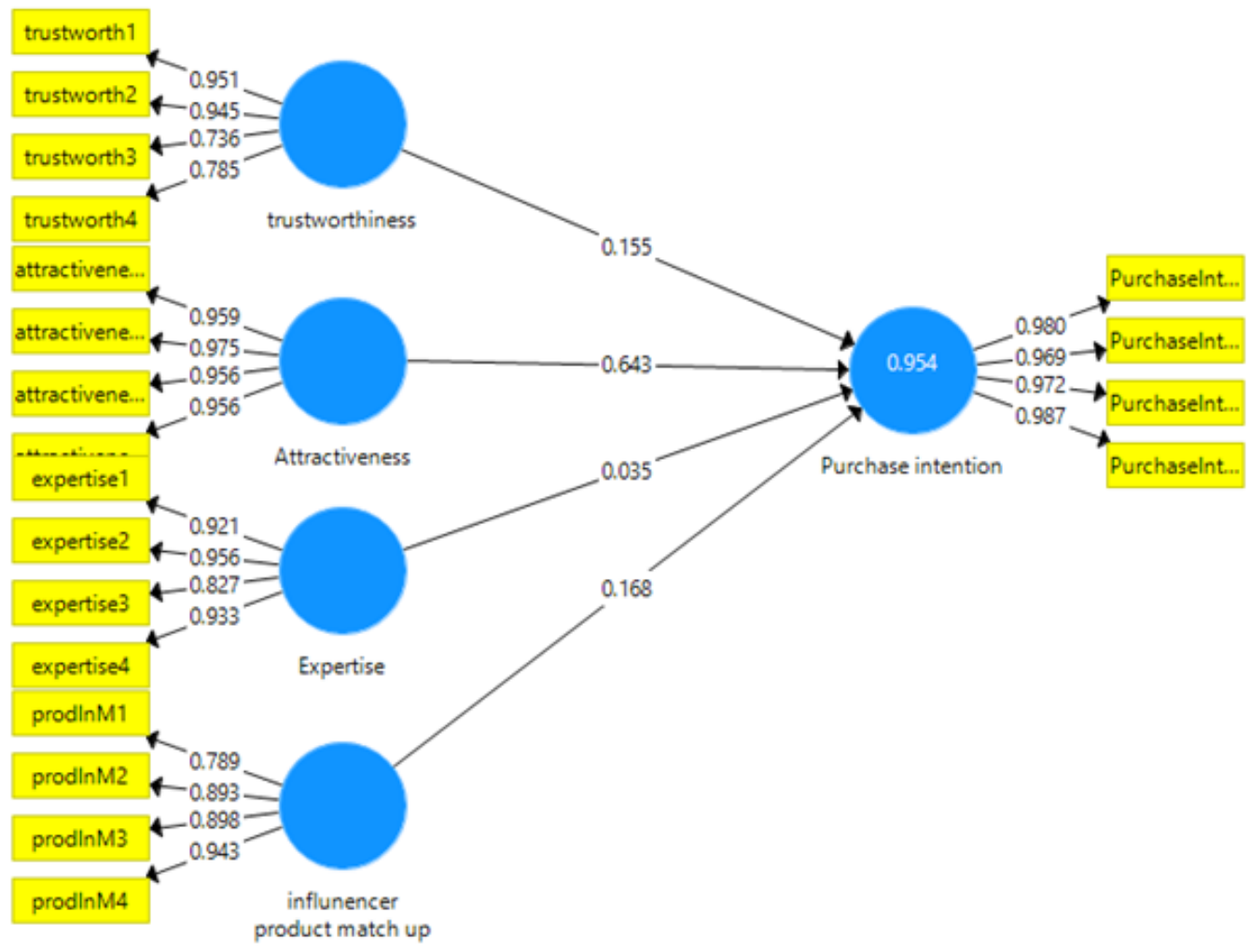




\section{Reliability of Measurement Instrument}

The cronbach's alpha for trustworthiness, attractiveness, expertise, influencer product match up and purchase intention are $0.973,0.931,0.984,0.906$ and 0.878 respectively which are acceptable and shows that the instrument is reliable. Further evidence of reliability is clearly showed as presented in table 2 which details the composite reliability, rho A and average variance extracted scores of various factors. Composite reliability is a test of convergent validity in a reflective model. CR of all latent variables is greater than the acceptable limit of 0.7(Carmines and Zeller, 1988). AVE depicts the average communality for each latent variable in a reflective model. The average- variance extracted for all the factors is greater than or equal to 0.5 acceptable limit which means that factors should explain at least half the variance of the respective indicator (Fornell \& Larcker, 1981).

Table 2: Validity and Reliability Analysis

\begin{tabular}{lcccc}
\hline & $\begin{array}{c}\text { Cronbach's } \\
\text { Alpha }\end{array}$ & rho_A & Composite Reliability & (AVE) \\
\hline Attractiveness & 0.963 & 0.974 & 0.980 & 0.925 \\
Expertise & 0.911 & 0.947 & 0.951 & 0.829 \\
Purchase intention & 0.974 & 0.984 & 0.988 & 0.955 \\
Influencer product match up & 0.906 & 0.936 & 0.934 & 0.779 \\
Trustworthiness & 0.878 & 0.917 & 0.918 & 0.739 \\
\hline
\end{tabular}

\section{Construct validity}

Construct validity is the extent to which a set of measured variable actually reflects the latent construct they are designed to measure (Hair et al., 2006). If the topmost number (square root of AVE) in any factor column is higher than the numbers (correlations) below it, there is established discriminant validity as seen in table 2

Table3: Discriminant validity (Fornell-Larcker Criterion)

\begin{tabular}{llllll}
\hline & Attractiveness & Expertise & $\begin{array}{c}\text { Purchase } \\
\text { intention }\end{array}$ & $\begin{array}{c}\text { influencer } \\
\text { product } \\
\text { match up }\end{array}$ & trustworthiness \\
\hline Attractiveness & 0.902 & & & & \\
Expertise & 0.791 & 0.901 & & & \\
Purchase intention & 0.831 & 0.797 & 0.877 & & \\
Influencer product match up & 0.787 & 0.783 & 0.602 & 0.883 & \\
Trustworthiness & 0.802 & 0.863 & 0.740 & 0.813 & 0.859 \\
\hline
\end{tabular}

\section{Hypothesis Testing}

Impact of social media influencer on purchase intention $\mathrm{H} 1$ to $\mathrm{H} 4$ was examined using structural equation model via Smart-Pls. The structural model with trustworthiness, expertise, attractiveness, Influencer product matchup and purchase intention were dimensions respectively is shown in figure 1. Hypothesis testing was done by observing the T.statistics and P-Values. The hypothesis shall be accepted if P-Value values is $<0.005$. Based on the data referenced above in table.3, attractiveness has a significant effect on purchase intention $(t=12.7, \mathrm{P}<0.05)$, trustworthiness has significant and positive effect on purchase intention $(\mathrm{T}=4.34, \mathrm{P}<0.05)$, influencer product match-up has significant and positive effect on purchase intention $(\mathrm{T}=3.37, \mathrm{P}<0.05)$ while expertise has no significant effect on purchase intention $(\mathrm{T}=1.019, \mathrm{P}>0.05)$. 
Table 4: research hypothesis test result

\begin{tabular}{llll}
\hline Hypothesized relationship & T. Statistics & P Values & Outcome \\
\hline Attractiveness -> Purchase intention & 12.692 & 0.000 & Significant \\
Expertise -> Purchase intention & 1.019 & 0.309 & Un-significant \\
influencer product match up -> Purchase intention & 3.369 & 0.001 & Significant \\
trustworthiness -> Purchase intention & 4.345 & 0.000 & Significant \\
\hline
\end{tabular}

\section{Discussion}

Having tested the stated hypothesis, it was found out that some of the hypotheses were supported while one was not supported. Based on the finding, H1 was supported which is congruence with the extant literature that found that attractiveness has a positive and significant effect on purchase intention (Satria et al., 2019). Attractiveness is one of the elements of source credibility in harmony with theory of Ohinian (1991). Attractiveness of an influencer has shown to significantly predict purchase intention. More so, this finding is opposed by the finding of (Till \& Busler, 1998; Lim, 2017) which found that social media influencers' attractiveness has a little or insignificant effect on purchase intention.

Secondly, source trustworthiness of social media influencer predict social media users purchase intention therefore, H2 was supported. Finding of this study is congruous to the findings of scholars (Onu et al., 2019; Satria et al., 2019). This translates that social media users trust influences their purchase intention. Thirdly, the finding show that source expertise has no effect on purchase intention hence H3 was unsupported. This harmonizes with retrospective studies (Lim, 2017) which found source expertise is not a predictor of purchase intention. This translates that consumer are not interested how expert an influencer is but rather interested in other dimension other than source expertise. Furthermore, some studies (Evans, 2013; Ha et al., 2017; Pham et al., 2015) found source expertise to be a strong predictor of purchase intention. Finally, as shown by the study, influencer product match-up has significant effect on purchase intention. Consumers are more interested and believe influencers who promotes product that matches their lifestyle (Fleck et al., 2012). H4 was accepted which is in harmony with the finding of retrospective studies (Ha et al., 2017; Satria et al., 2019). Social media users inferred that perceived congruency between social media influencer and product can impact their purchase decision. More so, social media users' shows to be confident if the product matches influencers image (Ha et al., 2017).

This study focused on the use of source credibility to examine customer purchase intention amongst social media users. This study extended the use of source credibility model in a totally different context other than celebrity endorsement. From the outcome of the study, it was found that attractiveness, trustworthiness and influencer and product match-up have significant predictive effect on purchase intention while expertise has no significant effect on purchase intention. This finding is contrary to common outcome which says that expertise has a significant effect on purchase intention with some studies tagging it the most important predictor of consumer behavior (Evans, 2013; Ha et al., 2017; Pham et al., 2015). This contradiction could be attributed to contextual change in application of source celebrity model which as opined by Biswas, Biswas \& Das (2006) states that social media influencer need not to be an expert to successfully influence consumer behavior hence supports the dismissal of supposed irrelevant construct Expertise. This study has investigated the application of source credibility model in social media facet thus, propose a new modified model of source credibility which disproves the critical importance of source expertise and upholds the importance of other three constructs with emphasis amongst social media influencers' domain (Lim, 2017). 


\section{Conclusion}

In an era where social media activities has gained traction and has given organizations appreciable exploding exposure that perhaps helps in achieving stipulated goals has been the major concern of every organization. Thus, manager has seen the indispensability of social media and its component. This study offer managers quantum pragmatic considerations in choosing social media influencer specific for promotion to gain huge competitive advantage in the ever competitive market. It is the manager's discretion to choose from the pool of option the right set of mix to look out from the influencer to achieve the optimum result from the influencer. This selected influencer should be well equipped to attract, engage and flourish the audience with captivating message about the organization and its product.

Generally, organization employs the services of social media influencers' to enhance their coast and increase their customer base. Plethora of studies have shown the efficacy in achieving heighten customer base from social media influencers. But then, organizations need to identify the right set of tools that performs most for them. Manager should be wary when seeking to employ the services of social media influencers as they can make or mar the performance of and organization. Foremost, to effectively harness the potentials of social media influence, organization should sort and seek out influencers with huge audience (fan base) with engaging audience. Furthermore, audiences are stringently interested in influencer's trustworthiness; it goes a long way to decide what the audience believe; do they totally believe with the information you are passing or just there to catch fun on your page? Organizations should painstakingly ensure that any contracted influencer has an existing unfathomable trust level which translates to audience believing totally in assertions of the influencer. More so, attractiveness has shown to be one of the elements that lure people into listening to influencers' assertion of promotional campaigns. Attractiveness can be seen from physical, classy and content attractiveness (Hearn \& Schoenhoff, 2016). Depending on what the organization deal on, influencer should be chose based on the best combination that will get the best result for the product. When promoting beauty care products, physical and classy is best form of attraction, when an organization renders services, content attraction will go a long way in influencing the consumers.

Therefore, organization should seek out attraction that works for their product and make do with it. Furthermore, influencer and product matchup should highly be considered when choosing an influencer as it shows to be a strong factor that customer look out for prior purchase. It is evident that some influencers are suitable for some product while some are highly incongruous with the product. Example of a congruous matchup depicts the use of a footballer as a sport betting influencer. Influencer product matchup is pivotal in social media influencing, if audience does not feel that the influencer is suitable for the product, they became passive listener or totally ignore the disseminated promotion. To this end, organizations should not use generic influencer rather; they should critically choose an influencer that is congruous with the product. Contrarily, expertise of an influencer could somewhat be ignored and focus on other dimensions that proved to have significant predictive effect on consumer purchase decision. As a point of departure, to effectively achieve the opportunities in social media influencing, organizations should strategically combine these stated recommendations to ensure maximum harness of domiciled potentials.

Businesses have evolved from brick and mortar to a global business village where all business activities can be performed over the cyber space simultaneously and at ease. This has enabled businesses make customers beyond boundaries. This disruption has steadily evolved strategies employed by organizations to communicate with intended audiences. One of the evident strategic changes is paradigm shift from major celebrity endorsement to conventional social media influencers (Parry 2018). 
Furthermore, studies have employed the use of Ohinian model of source credibility to evaluate effect of celebrity endorsement on purchase intention from customer's perspective (Corina, 2010; Fred, 2015). Specifically in this context, this study seeks to expand the horizon of source credibility by unprecedentedly employing the model empirically in the spectrum of social media influencers. With similar outcome, this result should be applied in a formal industrial setting for a better achievement of stated objectives.

This study, social media influencer and purchase intention is obviously limited to generic users of social media channels. Further study can critical study any social media channel; Facebook, twitter or Instagram. More so, it is limited to users of social media in Anambra state which does not connote and is not a true representation of the population. We looked at the direct relationship between social media influencer and purchase intention; other factors can mediate and moderate the relationship. These moderating or mediating variables like technology adoption intention and perceived risk can be inculcated to have a holistic view of such extended study. Finally, more reciprocating studies can be done from other states and countries to additionally establish a relation and take a stand in the existing argument regards the predictive or non-predictive effect of influencer expertise.

\section{Conflict of Interest}

Author(s) declares no conflict of interest while making this article.0

\section{References}

Ashe-Edmunds, S. (2017). What Is the Right Marketing Mix for Event Marketing?.

Belch, G.E., \&belch, M.A (2004). Advertising and Promotion: An integrated marketing communications perspective 6th, New York: NY: McGraw-Hill.

Bhasin, B. (2018). What is purchase Intention. Marketing management articles. DOI. Marketing.com/purchaseintention/.

Biswas, D., Biswas, A., \& Das, N. (2006). The differential effects of celebrity and expert endorsements on consumer risk perceptions. The role of consumer knowledge, perceived congruency, and product technology orientation. Journal of Advertising, 35(2), 17-31.

Clement J. Number of monthly active Facebook users worldwide as of 4th quarter 2019. https://www.statista.com/ statistics/264810/number-of-monthly-active-facebook-users-worldwide/. (Consulted March 15 2020).

Corina, S. (2010). Marketing communication in online social programs: Ohanian model of source credibility. Journal of Empirical Generalisations in Marketing, 1(1), 778-784.

Erdogan, B.Z., baker, M.J., \& Tagg, S. (2001). Selecting celebrity endorsers: The practitioners' perspective. Journal of Advertising Research, 41(3), 39-48.

Evans, R. B. (2013), production and creativity in advertising. Financial time management;

Ferberg, K., Graham. K., McGaughey. k., \& Ferberg, L. (2010). Who is a social media influencer? A study of public perceptions of personality. Public Relation review

Fleck, N., Korchia, M., \& Le Roy, L. (2012)," celebrities in advertising: looking for congruence or likability?" Psychology \& Marketing, 29 (9).

Fred, S. (2015). Examining endorsement and viewership effects on the source credibility of YouTubers.

Forell c. \& D. F. larcker (1981). "Evaluating Structural Equation Models with Unobservable Variables and Measurement Error". Journal of Marketing Research, 18, 39-45.

Ge, J., \& Gretzel, U. (2018). Emoji rhetoric: A social media influencer perspective. Journal of Marketing Management, 34(15-16), 1272-1295.

Ha, M.N., \& Lam, N.H (2017). The effect of celebrity endorsement on customer attitude towards brand \& purchase intentions. International journal of economics and financial, 6, 61-77.

Hearn, A., \& Schoenhoff, S. (2016). From celebrity to influencer. A companion to celebrity. Wiley: London, 194212.

Internet world statistics (2020, Jul 03), [Web page]. World internet penetration. Retrieved from https:// internetworldstats.com/stats.htm 
Johnson, T.J. \& Kaye, B.K. (2004). Wag the blog: How reliance on traditional media and the internet influence credibility perception of weblogs among blog users. Journalism \& Mass Communication Quality. 81(3), 622-642.

Kamins, M.A. (1990). An investigation into the match-up hypothesis in celebrity advertising: when beauty maybe only skin deep. Journal of Advertising, 19, 4-13.

Kumar, S., Zafarani, R., \& Liu, H. (2011, August). Understanding user migration patterns in social media. In Proceedings of the AAAI Conference on Artificial Intelligence (Vol. 25, No. 1).

Langmeyer, L., \& Shank, M. D. (1994). Does personality influence brand Image?. The Journal of psychology, $128(2), 157-164$.

Lim, X.J., Radzol, A.R.BA., Cheah, J.H.I., \& wong W.M (2017). The impact of social media influencer on purchase intentions and the mediation effect of customer attitude. Asian Journal of Business Research, Vol.7.

Liu, M. T., Huang, Y. Y., \& Minghua, J. (2007). Relations among attractiveness of endorsers, match-up, and purchase intention in sport marketing in China. Journal of Consumer Marketing.

More, J. S., \& Lingam, C. (2019). A SI model for social media influencer maximization. Applied Computing and Informatics, 15(2), 102-108.

Morwitz, V. (2012). Consumer purchase intentions and their behaviours. Foundation \& Trend in Marketing, 7, 3, 181-230.

Nam, G.L \& Dan, H.T (2018). Impact of social media influencers marketing on consumer at Ho Chi Minh City. International Journal of Social Science and Humanities Invention, 5(5), 4710-4714.

Ohanian, R. (1991). The impact of celebrity spokespersons' perceived image on consumers' intention to purchase. Journal of Advertising Research, 31(1), 46-54.

Onu, C.A., Goodluck, N., \& Adegbola, E.A (2019). The effect of celebrity physical attractiveness and trustworthiness on consumer purchase intentions: A study of Nigerian consumers. Management Science Letters, 9, 1965-1976.

Pang, A., Yingzhi Tan, E., Song-Qi Lim, R., Yue-Ming Kwan, T., \& Bhardwaj Lakhanpal, P. (2016). Building effective relations with social media influencers in Singapore. Media Asia, 43(1), 56-68.

Parry, N. (2018, Feb 28). Why social media influencers are more powerful than celebrity endorsement [Web page]. Retrieved from https://www.smallsquare.com/influencers-vs-celebrity-endorsements/

Peetz, T. B. (2012). Celebrity athlete endorser effectiveness: Construction and validation of a scale.

Pham, T.M.L, \& Nguyen, T.V (2015). The effect of celebrity endorsement in advertising on consumer attitude. Journal of Economics and Development, (215), 78-86.

Rahayu, O., \& Arifin, W. (2020). The Effect of Source Credibility, Source Attractiveness, Product Matchup, and Meaning Transfer toward Purchase Intention Mediated by Consumer Attitude on Fashion Industry in Indonesia. Ibuss Management, 8(2).

Satria, A.D., Jatipuri, S., Hartanti, A.D., \& Sanny L. (2019). The impact of celebrity endorsement by social influencer Celebgram on purchase intention of generation $\mathrm{Z}$ in fashion industry. International Journal of Recent Technology \& Engineering, 8, 397-404.

Shiffman, L., \& Kanuk, L. (2000). Consumer learning. Consumer Behavior, 192.

Shimp, T (2000). Advertising promotion: supplemental aspects of integrated marketing communications. Fort worth, TX: Dryden Press.

Talavera, M. (2014). 10 reasons why influencer marketing is the next big thing. Retrieved March 10, 2016 from http://www.adweek.com/socialtimes/10-reasons-why-influencer marketing-is-the-next-big-thing/623407

Till, B.D., \& Buster, M. (1998). Matching products with endorsers: attractiveness versus expertise. Journal of Consumer Marketing, 15, 576-586.

Wielki, J. (2020). Analysis of the role of digital influencers and their impact on the functioning of the contemporary on-line promotional system and its sustainable development. Sustainability, 12(17), 7138.

Xinjean, L. \& Hwa, C.J. (2019). The Impact of social media influencers on purchase intention and the mediation effect of customer attitude. Asian Journal of Business Research, 7, 3-11.

Zhao, X., Zhan, M., \& Liu, B. F. (2018). Disentangling social media influence in crises: Testing a four-factor model of social media influence with large data. Public Relations Review, 12, 44(4). 